\title{
TISSUE CULTURE AS A PLANT PRODUCTION TECHNIQUE FOR FRUIT CROPS AND PLANT PART USED FOR PROPAGATION
}

\author{
Rahul R. Rodge and Pravin Patil \\ Lovely Professional University, \\ Department of horticulture, Lovely Professional University, Phagwara Punjab
}

\begin{abstract}
The culture of plant tissue refers to the growth and multiplication in aseptic and regulated environments of cells, tissues and plant organs on specified solid or liquid media. In the fields of agriculture, horticulture, forestry and plant breeding, plant tissue culture has been commonly employed. it is an applied biotechnology used for mass proliferation, extinction of viruses, development of secondary metabolites and In-vitro cloning of plants. Plant tissue culture, slow growth and cryopreservation, also known as long-term preservation are also known as, has been extensively used for the preservation of endangered plant species., through short and medium-term conservation. In a suitable culture medium, a whole plant may be regenerated from a small tissue or plant cell. under controlled environment. Commercial technology is mostly based on micro propagation, where rapid proliferation is performed from process cuttings, axillary buds, somatic embryos, cell clumps in suspension cultures, and bioreactors to a small degree.
\end{abstract}

Keywords: In vitro; micropropagation; fruit crops; plant part used.

\section{INTRODUCTION}

Tissue culture to be the in vitro aseptic culture of cell, tissue, organs of hole plants under controlled nutritional and environment conditions species of plant are also made the initial clones of the genotype chose are true-to type. The regulated condition provide an atmosphere to the culture that is conductive of the growth and multiplication. sufficient availability of nutrients, medium the $\mathrm{PH}$, adequate temperature and the appropriate gaseous and liquid atmosphere are protected by these conditions. for large-scale plants biotechnology is commonly used sprading. the techniques of plant tissue culture have become important industrial techniques. relevance in the field of plant propagation, elimination of pathogens, plant growth and secondary metabolite processing in recent years , in addition to their use as a research method. Small tissue parts (called explants) in a period exceeding, hundreds or even thousands of plants may be grown. A one plant material could be altered in a comparatively short period of time and space into too many thousand plants under controlled conditions, on a year-round basis, independent of season and temperature. Due to improved multiplication coefficients and low requirements, endangered and uncommon species are efficiently generated and preserved by micropropagation.on the quantity of original plants and property. In addition, for developing somaclonal and gametoclonal variants, plant tissue culture is considered the most significant technique for crop development. With well-adapted high-yielding genotypes, the vitro propagation technique has a significant potential for growing excellent quality plants, isolating useful variants With increased capacity for disease resistance and stress tolerance. Types of these kinds callus cultures give rise to copies that have distinct inherited characteristics from those of parent plants as a function of the chance of somaclonal heterogeneity.(Altaf Hussain et al., 2011)

Production of cells,tissues, organs or entire plants in maintained environmental and nutritional production process is the in vitro aseptic production of plant tissue.

*Corresponding author: rahul.r.rodge123@gmail.com 
(Thorpe 2007) Also can be generated. The resulting clones adapt to the genotype type chosen. The protected areas include an atmosphere for environment and culture favorable to their development and proliferation of growth. these criteria include specifications which include adequate nutritional supply, optimal $\mathrm{pH}$ temperature and ample gaseous temperatures and gaseous properties climate of liquid.the culture of plant tissues there is systematic use of technologies for massive plant multiplication scale. other than their utilisation plant tissue culture as a science medium over modern years, methods have been of strong industrial significance in the field of propagation of seeds, removal of pests, cultivation, enhancement and creation of secondary growth metabolites It is possible to use small pieces of tissue (called explants) are produced in a continuous process to generate thousands and hundreds of, thousands of plants a it is possible to multiply a single explant into many, In a relatively short time period, a thousand plants and capacity in controlled situations, irrespective of season and temperature, on a basis over round the year (Idowu,2009)

Endangered and different plants have been grown successfully and processed due to high coefficients, multiplication of micropropagation and low number requirements and area of initial plants additionally, the culture of plant tissue is known to be the most powerful cropping technology Improvement of somaclonal production by gametoclonal versions the science of micropropagation has a wide variety of Potential to generate superior quality plants Isolation of desirable variants in well-adapted forms high-yielding, better disease resistant genotypes of capacities for resistance and stress tolerance (Brown and Thorpe, 1995) any kind of sort of callus communities are the origins of clones that have hereditary attributes that are different from those due to the probability of parent plants somaclonal heterogeneity occurrence (George 1993), Which results in the growth of improved varieties, which are economically important, Industrial products by way of plants the strategies of micropropagation include some advantages over the conventional techniques of crop propagation, cutting, grafting, Air-layering etc, and that is the fast proliferation of Methods which can lead to the generation of plants free from viruses (Garcia-Gonzales et al., 2010) Coryodalis yanhusuo, a significant one somatic plants have been propagated by medicinal plants from tuber-derived callus of embryogenesis creating disease-free tubers (Sagare et al., 2000). Meristem Tip banana plant culture bunchy Top Virus (BBTV) Devoid brome mosaic The Brome mosaic virus (BMV) as well as the Brome mosaic virus was produced (El-Dougdoug and El-Shamy, 2011), pathogen free germoplasma Increase in up to $150 \%$ yield of virus-free potatoes was In controlled conditions obtained (Singh, 1992).

The plant tissue culture medium provides nutrients required for normal growth and plant growth, mainly consisting of macronutrients, vitamins, micronutrients, other organic components, growth components, in plants regulators, origins of carbon and certain gelling processes agents, if the medium is solid. Murashige the most widely used Skoog media (MS media) is widely used for vegetative reasons, in vitro production of multiple plant species it is also important to the $\mathrm{pH}$ of the media that impacts on plant development as well as development if regulaotrs for plant growth. It is modified according to the range from 5.4 to 5.8 Liquid media should be used for both the solid and the liquid for culture. The composition of the medium has a massive impact on the initial explant, particularly the medium nitrogen content and plant hormones. Plant Growth Regulators (PGR) plays an important role in the determination of the pathway of plant cells and growth tissues in the centre of culture. Auxins, the the most frequently contained cytokinins and gibberellins are commonly used regulators growth of plant. amount and dosage of hormones used depends largely mostly on types of plants, plant types, cultured tissues or organs and the purpose of the experiment. (Ting 1982). Auxins and the most commonly used plant growth cytokinins are plant tissue culture regulators as well as the amount depending upon the type of culture created or regenerated by the high concentration of auxin typically favours the production of root concentrations, whereas the increased levels of cytokinins facilitate the proliferation of shoots. In rebaudiana stevia, maximal root induction and proliferation have been recorded when the media is supplemented with $0.5 \mathrm{mg} / \mathrm{l}$ NAA(Rafiq et al . ,2007).

Usually, cytokinins promote cell growth and division enable the development of shoots and the proliferation of axillary shoots high cytokinin to the ratio of auxin encourages the proliferation of shoots while the ratio root formation effects from high auxin to cytokinins (Rout et al., 2004) Initiation shoot and max multiplication were reported once the black pepper callus was transported to medium augmented with BA at $0.5 \mathrm{mg} / \mathrm{l}$ of BA level. (Hussain et al., 2011).

As an alternative method of vegetative proliferation, tissue culture is becoming Including plants. plants grown in vitro are typically free of bacteria and fungi diseases. now, the most effective and widely used procedure has been improved. replication by axillary bud . Axillary buds are 
found on the axis of the leaves. The dormancy of axillary buds can be a mixture of cytokinin and Auxin using optimal concentrations of cytokininin tissue culture. be ruptured they develop into shoots until the dormancy is broken. By using media containing optimal plant growth regulator concentrations, they it is possible to multiply very easily. culture of current plant tissue is performed under purified air under aseptic living conditions for plants naturally, they are affected by the atmosphere on their surfaces (and often indoors) with microorganisms, thus the beginning of surface sterilisation materials (explants) are essential (usually alcohol) in chemical solutions. Today, since it is unsafe to use and impossible to dispose of, mercuric chloride is often used as a sterilising plant agent. then, explants are usually placed on a solid culture medium 's surface, but are often placed directly into a liquid medium, particularly when cultures Suspension of cells was performed. solid and liquid media are largely made up of sodium materials, with a few nutrients, vitamins and plant hormone. that are herbal. Strong media sources are with the addition of a gelling agent, typically prepared from liquid media, purified agar. the structure of the medium, the plant in particular, hormones and origins of the influence of nitrogen (nitrate vs ammonium salts or amino acids) on tissue morphology derived from of the initial explant are important.

A abundance of Auxin, for example, will always result in a roots proliferation, while an excess of cytokinin can produce shoots. an unorganised equilibrium of both auxin and cytokinin may also produce cell growth or callus, but as culture expands, the maturation morphology may depend on both species of plants and medium composition, generally sections are broke off and distributed to new media (subcultures) to enabling development or changing the culture's morphology. The strength experience is important in tissue culturist determining which pieces to judge. culture and which one to discard.

\section{Important history about plant tissue culture}

- 1902: In vitro cell culture technology suggested by Haberland

- 1904: Hanning has developed embryos of many species,

- 1922: Culturated successfully by Kolte and Robbins on root and stem tips

- 1926: Plant growth harmone IAA indole acetic acid was first discovered.

- 1934: Implemented VITBB growth supplement media for tissue culture

- 1939: Callus culture Proliferation
- 1941: For the cell division in Datura, coconut milk was first used.

- 1946: By shoot tipi culture, Ball grew an whole lupinus plant

- 1960: Kinetin was discovered by Skoog and miller as harmone to cell division

- 1960: The enzymatic cooking of the first toisolate protoplast was cell wall degregation

- 1960: The test tube fertilisation technology was proposed by Kanta and Maheshwarararar

- 1962: Murashige and skoog accumulate high salt concentrations in medium MS.

- 1964: First haploid plant developed by Guha and Maheshwari datura (Anther Culture) from pollen grains

- 1922: Cultured by Kolte and successfully on Robinsot and stem tips

- 1955: Kinetin was defined by Skoog and miller as a cell division harmone.

\section{Importance of tissue culture}

- It is easy to produce a large number of plantlets, in a relatively small time and space. generated on the basis of a single explant.

- Taking an explant usually may not destroy the mother plant, but sometimes and endangered plants can be cloned successfully.

- Relevant characteristics could be directly taken from the culture set-up (in vitro), thereby reducing the amount of space available for field trials.

- Once established, a line of plant tissue culture may provide a continuous line

- the year-round availability of young plants

- The time needed is considerably reduced, there is no need to wait for the entire crop development life cycle. For species that have generations that are long time, lower seed production volume, or seeds that are not readily available germinate, it is possible to replicate rapidly.

- Generally free of bacterial and fungal plants, in vitro developing plants diseases. Virus eradication and virus-free management of plants state.

- This encourages the worldwide transport of plants boundaries

- Tissue banks of plants can be frozen and then regenerated by tissue culture. It retains the collections of pollen and cells from which plants are can be propagated. 
Stages of tissue culture process

1. Nutrient solution preparation: The semi-solid solution is prepared in double distilled water containing macroelements, microelements, amino acids , vitamins, sources of calcium, sources of carbon such as sucrose, and phyto-hormones.

2. Aseptic culture establishment: An rapidly growing shoot tip of an axiliary or terminal bud or shoot tip of a plant is usually the starting material for the process. 3.Inoculation: Inoculation under aseptic conditions is performed. Explants or micro shoots are passed to the sterilised nutrient medium in this process.

4.Plant development in growth room: The bottles are sealed after inoculation of the plant tissue and moved red into the growth room to activate the development phase at $25 \pm 2$ o Can 50 to 60 percent relative humidity under light sources (fluorescent light 1000-2000 lux). 5. Micro plant hardening: Due to very high humidity within the culture vessel and artificial growth conditions the plantlets are re tendered and thus not prepared for coping with the field condition.

\section{Tissue culture of fruit crops}

Traditionally, most fruit-bearing plants have been propagated using vegetative techniques to retain attractive qualities. micropropagation methods may be used to enhance, or can be employed in the future replace the methods of vegetative propagation currently in use In this is also happening in many parts of the world. for examples, the bulk of all commercially processed strawberries are grown from In some European countries, in vitro-derived plantlets.

\section{MANGO}

Clonal propagation through tissue culture facilitates rapid multiplication, easy storage and safe exchange of germplasm. While some success has been achieved with somatic embryogenesis using nucellar tissue of mango In general, the source of shot tips was 8-16 year-old genotypical trees'Alphonso ',' Banganapalli ',' Totapuri 'and' Arka Anmol '. Uniform shoots of the kind with a single leaf rosette as the lower ones were otherwise picked at the tip, rapid medium discoloration caused by cutting petioles. (Thomas, Pious, et al., 1997).

\section{BANANA}

The banana, in the world as well as in India, is the fourth most common fruit crop. In banana vitro propagation has provided outstanding benefits, including fast multiplication. level, physiological uniformity and diseasefree content availability during the year, in contrast with traditional plants, higher development in the earlier stages. An effective in banana plants, the micropropagation method was developed using sword sucker explants. Shoot tips containing rhizome tissue were isolated, measuring 2.0 to $3.0 \mathrm{~cm}$ in size. The surface sterilized for 15 to 20 minutes with chlorine-saturated purified water and for 5 to 7 minutes with $1.0 \%$ mercuric chloride. (Govindaraju, et al.,2012)

\section{PAPAYA;}

Shoot tips have been used as plant material from fruit bearing female papaya tree (c.v. Honey Dew) Shoot tips (length of 2-3 cm).An effective protocol for papaya (Carica papaya) in vitro propagation was created. By culturing shoot tips on Murashige and Skoog (MS)-medium supplemented with $0.5 \mathrm{mg} / \mathrm{l}$ (NAA) naphthalene acetic acid + $0.5 \mathrm{mg} / \mathrm{l}$ (BA) benzyl adenine, shoot cultures were obtained. $2 \mathrm{mg} / \mathrm{l} \mathrm{NAA}+0.6 \mathrm{mg} / \mathrm{l}$ (lBA) indole butyric acid + $60 \mathrm{mg} / \mathrm{l}$ adenine sulphate was the best for shoot multiplication among the various combinations of growth regulators applied with and without adenine sulphate to culture medium. (M. M. Saker et al., 1999)

The propagation studies were conducted by improving the release of axillary buds in the CO-5 variety of Papaya. As an explant for in vitro propagation, apical buds and lateral buds from seedlings and mature plants are being used. Various treatments of plant growth compounds for culture establishment and shoot multiplication have been subjected to explants from papaya varieties and hybrid (Bindu B et al., 2015)

\section{STRAWBERRY}

Stable and high-yielding strawberry plantlets for cultivation require mass processing of standard propagules to produce basic material for the establishment of largescale plantlets. one of the productive means of achieving this goal is micropropagation. The major effects of poor strawberry production are continuous planting of runners from old mother plants that are vulnerable to diseases \& viruses for five or more years and the absence of appropriate planting materials. Efficient procedure for shoot regeneration, proliferation and rooting for nodal segments of chandler, Oso-Grande and Cama-Rosa strawberry (Fragaria $\mathrm{x}$ ananassa) cultivars have been produced. (Mir, J. I., et al.,2010).

A strawberry CV micropropagation protocol. Through axillary shot proliferation from runner tips, Sweet Charlie was standardised. For the induction of multiple shoots and daughter runners from runner tips, medium augmented by TDZ (1 mg / L) alone was favourable. (Rekha, R et al.,2012) An successful method of disinfection procedure and micropropagation has been developed with an enhanced survival rate of strawberry explants and decreased phenolinduced browning. three genotypes had a rate of survival 
with between 89.2-100 percent. As cultured under dim light (500 lux), Shoot tip was able to grow into plantlet on a hormone-free MS medium.( Ko, C., Al-Abdulkarim et al.,2009).

\section{POMEGRANATE}

Reliable and reproducible techniques have been developed to achieve healthy and well-formed plants from nodal pomegranate (Punica granatum L) cv 'Bhagava' explants. At full strength, Murashige and Skoog (MS) and Woody Plant Medium (WPM) nodal segments have been cultured in 2 distinct media.(Patil et al.,2011).

The explants were taken from 7-year-old fruiting trees of cv. (shoot tip and nodal segment). cv. Ganesh By regular subsuting of explants to media augmented with the same hormonal concentrations, the browning of cultures was regulated.(MurkuteA.A et.,2004).

Murashige and Skoog Medium (MS medium, 1962) were mounted on Leaf, Shoot apex and Nodal segment explant of pomegranate, supplemented with various concentrations of cytokinins and auxins for callus induction. (Choudhary, R., et al.,2018)

\section{APPLE}

Effective in vitro propagation of Cvs Redspur and Goldspur parentage dwarf and semi-dwarf seedling apple trees has been achieved. The material was taken from orchard trees that were 9 years old. Shot tip explants were more readily identified in vitro when arising by freshly grafted shoots then when originally extracted from the trees of the orchard.( Jones, O. P., et al 1985)

The widely known shoot culture with the prevalence of axillary shoots is the In vitro method of propagation to preserve a clone 's genetic integrity during the last decade, such procedures have been commonly applied to apples; approximately 70 cultivars of apple rootstock and scion have now been recorded as successfully propagated by shoot culture methods (Jones, O. Pet al., 1993).

By culturing axillary bud on MS basal medium, effective in vitro propagation of clone rootstock apple MM106 was achieved. (Sharma et al.,2000)

\section{GRAPE}

The objective of the present study was to establish a protocol for the in vitro propagation of deGrasset, a grape rootstock characterised by high drought and salinity. Four compositions of the medium, MS, MS shoot development from nodal explants and MS-1 were tested with $1 / 2$ nitrates (MS-1), B5 and WPM. A significantly higher rate of shoot proliferation was provided by medium. (Mukherjee et al.,2010)
Reliable and reproducible treatment for grapevine (Vitis vinifera L.) micropropagation 'Muscat of Alexandria' cv. After surface sterilisation of the checked explants (shoot tips and internode segments) using sodium hypochlorite $(\mathrm{NaCl})$ at 0.52 and 0.78 percent for 15 and 20 minutes respectively, they were formed from shoot tips and internode segments.(Abido, A. I. A., et al 2010).

For the current analysis, four grape rootstocks with various genetic backgrounds were selected: Dogridge (Vitis champini), SO4 (V. riparia x V. berlandieri), H-144 (V. vinifera x V. labrusca) and 3309 C (V. riparia x V. rupestris). Explant canes were collected from five-year - old vines at Grape Germplasm Block, Main Experimental Orchard, IARI, New Delhi, New Delhi.(Alizadeh et al.,2010)

\section{CITRUS}

\section{MANDARIN}

For Citrus megaloxycarpa Lush., a highly acidic citrus cultivar from Manipur, India, an effective micropropagation protocol was developed. explant culture through shoot tip. when cultured on agarized Murashige and Skoog medium containing 0.25 to 2 mg L-1 N6 benzyl adenine (BA) alone and in combination with $0.50 \mathrm{mg} \mathrm{L}-1$ naphthalene acetic acid (NAA) or $0.50 \mathrm{mg} \mathrm{L}-1$ kinetin, the shoot tip explants formed numerous shoot buds.( Haripyaree et al., 2010).

The current study deals with the creation of an appropriate mandarin micropropagation protocol (Citrus reticulata L.) by means of cotyledon and juice vesicle direct propagation as an explant. The in vitro callus induction of leaf, stem segments and cotyledon system was collected from seedlings. (Badrelden et al.,2017).

\section{SWEETORANGE}

An successful method for in vitro plant regeneration using mature tissues of sweet orange cv from thin transversal stem sections explants (1-2 mm). Pera has been created. To determine the frequency of regeneration and size of buds, explants were cultivated in various media. When the explants were grown on Murashige and Skoog medium for 2 weeks and then moved to Woody Plant medium (WPM), a high percentage of explants (54 percent with 3.1 buds / explant) developing wide buds (1-4 mm) was observed.( Kobayashi, et al 2003).

\section{GUVA}

Plantlet regeneration from In vitro germinated seedling explants. multiple shoots were produced from Psidium guajava L. in vitro germinated (50 day-old) seedlings. Cv! Cv. From Safeda. Updated Murashige \& Skoog (MMS) 
medium with 6-benzylaminopurine (BAP), zeatin and gibberelic acid (GA3) supplementation, Zeatin $1.0 \mathrm{mg} / \mathrm{L}$ in combination with GA3 $0.5 \mathrm{mg}$ / L yielded the highest result (47.6\%) with (3.2) shoot regeneration per initial explant.

Micropropagation of guava from five years of bearing plants by shoot tip culture. shoot tips were cultivated on modified MS medium after sterilisation, supplemented with distinct concentrations and combinations of Lglutamin and BAP. When MS was combined with BAP 1 $\mathrm{mg} / \mathrm{L}$ and $500 \mathrm{mg}$ / L L-glutamine, the maximum number of shoots (72 per cent) was produced in plantlets. (Zamir et al.,2007).

\section{CONCLUSION}

One of the most significant components of applied biotechnology is tissue culture. For commercialization, effective in vitro propagation of plants is now being used. many laboratories for commercial purposes worldwide use of in vitro culture by national institutes rapid plant multiplication system, conservation of germplasm, elimination of pathogens, genetic manipulations, and for the production of secondary metabolites. yearly, millions plants are regularly processed in vitro. The great one by reducing the production cost per plant by implementing low-cost tissue culture, the ability of micropropagation for large-scale plant multiplication can be exploited. the introduction of protocols and the proper use of equipment and resources to decrease micropropagule unit costs development of plants without sacrificing quality.

\section{REFERENCES}

1. Abido, A. I. A., et al. "In vitro propagation of grapevine (Vitis vinifera L.) Muscat of Alexandria cv. for conservation of endangerment." Middle-East Journal of Scientific Research 13.3 (2013): 328-337.

2. Alizadeh, M., S. K. Singh, and V. B. Patel. et al "Comparative performance of in vitro multiplication in four grape (Vitis spp.) rootstock genotypes." (2010): 41-50.

3. Badrelden, Awatef. et al. "Establishment of in Direct Propagation of Mandarin (Citrus reticulata L) Using Tissue Culture." Egyptian Journal of Botany 57.3 (2017): 405-416.

4. Bindu, B. et al. "Micro Propagation of Papaya Variety CO-5." International Journal of Research 46 (2015).

5. Brown, D. C. W., and T. A. Thorpe. et al."Crop improvement through tissue culture." World Journal of Microbiology and Biotechnology 11.4 (1995): 409415.
6. Choudhary, R., et al. "In vitro callus induction from different explants in Pomegranate (Punica granatum L.)." Journal of Pharmacognosy and Phytochemistry 7.4 (2018): 2656-2659.

7. El-Shamy, M. M. et al. "Management of viral disease in banana using certified and virus tested plant material." African Journal of Microbiology Research 5.32 (2011): 5923-5932.

8. García-Gonzáles, Rolando, et al. "Plant tissue culture: Current status, opportunities and challenges." International Journal of Agriculture and Natural Resources 37.3(2010): 5-30.

9. Govindaraju, S., et al. "In vitro propagation of Banana (Musa sp-Rasthali variety) from sword suckers for its commercial production." Research in Plant Biology 2.5(2012).

10. Haripyaree, Adhikarimayum, et al. "In vitro propagation of Citrus megaloxycarpa." Envir. Exper. Biol 9 (2011): 129-132.

11. Hussain, A., Naz, S., Nazir, H., \& Shinwari, Z. K. (et al.2011). Tissue culture of black pepper (Piper nigrum L.) in Pakistan. Pak. J. Bot, 43(2), 1069-1078.

12. Hussain, Altaf, et al. "Plant tissue culture: current status and opportunities." Recent advances in plant in vitro culture (2012): 1-28.

13. Idowu, P. E., D. O. Ibitoye, and O. T. Ademoyegun. et al. "Tissue culture as a plant production technique for horticultural crops." African Journal of Biotechnology 8.16(2009).

14. Jones, O. P. et al."Propagation of apple in vitro." Micropropagation of woody plants. Springer, Dordrecht, 1993. 169-186.

15. Jones, O. P., et al. "Propagation in vitro of some dwarf apple trees." Journal of horticultural science 60.2 (1985): 141-144.

16. Ko, C., Al-Abdulkarim, A. M., Al-Jowid, S. M., \& AlBaiz, A. et al.(2009). An effective disinfection protocol for plant regeneration from shoot tip cultures of strawberry. African Journal of Biotechnology, 8(11).

17. Kobayashi, A. K., et al. "Plant regeneration of sweet orange (Citrus sinensis) from thin sections of mature stem segments." Plant Cell, Tissue and Organ Culture 74.1 (2003): 99-102.

18. Mir, J. I., et al. "Micropropagation of strawberry (Fragaria× ananassa)." Crop Improvement 37.2 (2010): 153-156.

19. Mukherjee, Papiya, et al. "In vitro propagation of a grape rootstock, deGrasset (Vitis champinii Planch.): 
Effects of medium compositions and plant growth regulators." Scientia horticulture 126.1 (2010): 13-19.

20. Murkute, A. A., Shanti Patil, and S. K. Singh.et al. "In vitro regeneration in pomegranate $\mathrm{cv}$. Ganesh from mature trees." Indian Journal of Horticulture 61.3 (2004): 206-208.

21. Nalawade, S.M., Sagare, A.P., Lee, C.Y., Kao, C.L. and Tsay, H.S., et al. 2003. Studies on tissue culture of Chinese medicinal plant resources in Taiwan and their sustainable utilization. Bot. Bull. Acad. Sin, 44(2), pp.79-98.

22. Patil, Vijay M., et al. "Micropropagation of pomegranate (Punica granatum L.)'Bhagava'cultivar from nodal explant." African journal of Biotechnology 10.79 (2011): 18130-18136.

23. Rafiq, M., Dahot, M. U., Mangrio, S. M., Naqvi, H. A., \& Qarshi, I. et al.(2007). In vitro clonal propagation and biochemical analysis of field established Stevia rebaudiana Bertoni. Pak. J. Bot, 39(7), 2467-2474.

24. Rekha, R., Pallavi Mandave, and Neelambika Meti. et al. "Micropropagation of strawberry cultivar Sweet Charlie through axillary shoot proliferation." Journal of Applied Horticulture 14.1 (2012): 71-73.

25. Rout, Gyana Ranjan. et al. "of Clitoria ternatea L." Biol. Lett 41.1 (2004): 21-26.
26. Saker, M. M., et al. "In vitro propagation of papaya (Carica papaya L.)." Arab Journal of Biotechnology 2 (1999): 235-244.

27. Shah, S. Tariq, et al. "In vitro regeneration of plantlets from seedlings explants of guava (Psidium guajava L.) cv. Safeda." Pak J Bot 40.3 (2008): 1195-1200.

28. Sharma, Mamta, Manju Modgil, and D. R. Sharma. et al. "Successful propagation in vitro of apple rootstock MM106 and influence of phloroglucinol." (2000).

29. Thomas, Pious, and M. B. Ravindra. et al. "Shoot tip culture in mango: Influence of medium, genotype, explant factors, season and decontamination treatments on phenolic exudation, explant survival and axenic culture establishment." Journal of Horticultural science 72.5(1997): 713-722.

30. Thorpe, Trevor A. et al. "History of plant tissue culture." Molecular biotechnology 37.2 (2007): 169180.

31. Ting, I. P. et al. (1982). Plant mineral nutrition and ion uptake. Plant Physiology. Addison-Wesley, Reading, Massachusetts, 331-363.

32. Zamir, Roshan, et al. "In vitro regeneration of guava (Psidium guajava L.) from shoot tips of mature trees." Pakistan Journal of Botany 39.7 (2007): 2395-2398. 